Article

\title{
On the Importance of Strengthening Moderate Beliefs in Climate Science to Foster Support for Immediate Action
}

\section{Zachary A. Wendling ${ }^{1, *}$, Shahzeen Z. Attari ${ }^{1}$, Sanya R. Carley ${ }^{1}$, Rachel M. Krause ${ }^{2}$, David C. Warren ${ }^{1}$, John A. Rupp ${ }^{3}$ and John D. Graham ${ }^{1}$}

1 School of Public and Environmental Affairs, Indiana University, 1315 East 10th Street, Bloomington, IN 47405, USA; E-Mails: sattari@indiana.edu (S.Z.A.); scarley@indiana.edu (S.R.C.); dcwarren@indiana.edu (D.C.W.); grahamjd@indiana.edu (J.D.G.)

2 School of Public Affairs and Administration, University of Kansas, 1445 Jayhawk Boulevard, 4060 Wescoe Hall, Lawrence, KS 66045, USA; E-Mail: rmkrause@ku.edu

3 Indiana Geological Survey, 611 North Walnut Grove Avenue, Bloomington, IN 47405, USA; E-Mail: rupp@indiana.edu

* Author to whom correspondence should be addressed; E-Mail: zwendlin@indiana.edu; Tel.: +1-812-855-2457; Fax: +1-812-855-7802.

Received: 27 October 2013; in revised form: 27 November 2013 / Accepted: 29 November 2013 / Published: 3 December 2013

\begin{abstract}
Whereas many studies focus on climate skeptics to explain the lack of support for immediate action on climate change, this research examines the effect of moderate believers in climate science. Using data from a representative survey of 832 Indiana residents, we find that agreement with basic scientific conclusions about climate change is the strongest predictor of support for immediate action, and the strength of that agreement is an important characteristic of this association. Responses indicate widespread acceptance of climate change, moderate levels of risk perception, and limited support for immediate action. Half of the respondents (50\%) preferred "more research" over "immediate action" $(38 \%)$ and "no action" (12\%) as a response to climate change. The probability of preferring immediate action is close to zero for those who strongly or somewhat disbelieve in climate change, but as belief in climate change grows from moderate to strong, the probability of preferring immediate action increases substantially; the strongest believers have a predicted probability of preferring immediate action of $71 \%$. These findings suggest that, instead of simply engaging skeptics, increasing public support for immediate action might entail motivating those with moderate beliefs in climate change to hold their views with greater conviction.
\end{abstract}


Keywords: climate change; public perception; regional studies; immediate action

\section{Introduction}

Americans are increasingly convinced that climate change is occurring [1]. However, public policy, particularly at the federal level, has lagged behind this movement in public opinion. Previous research on public opinion in the U.S. has shown high levels of climate change awareness coincident with persistently low levels of concern [2,3]. Despite evidence that the majority of Americans support various federal climate policies [4-6], this support has not translated into the adoption of comprehensive policy. Likewise, Americans have stated their willingness to accept voluntary behaviors to curb greenhouse gas (GHG) emissions [6], but actual behavior change is still limited. The lack of comprehensive political action may be partly explained by politicians' misunderstanding of their constituencies' sentiments on this issue [4], but the broader problem of inaction may be based on a number of barriers identified in the literature on the value-action gap [7,8]. Rather than exploring these specific barriers, this study establishes a connection between beliefs about climate change and the pervasive reluctance among Americans to support immediate action on climate change.

Many factors influence individuals' support for action on climate change, and previous research has shown that the single most important factor is their belief about climate change [9]. This suggests two possible routes to understanding and increasing support for climate action. One approach, investigated by Bain, Hornsey, Bongiorno, and Jeffries [10], shows that beliefs of climate skeptics can be circumvented and policy support can be strengthened by focusing on the positive co-benefits of climate policy, such as improved quality of life and technological growth. An alternative route, and the one used in this study, involves investigating the factors associated with beliefs about climate change and assessing how those beliefs are associated with support for immediate action.

Rather than eliciting reactions to a detailed policy proposal or specific behaviors, this study, gauges the degree of public support for "immediate action." Thus, no particular policy proposals (e.g., a national carbon tax) are examined, because research has shown that specific policies can be divisive to segments of the population [11] and our study does not intend to gauge the reaction of respondents to particular actions on climate change. Rather, this study investigates the factors that predict whether survey respondents possess some degree of urgency in the need for climate action, especially the preference for "immediate action" over the desire to wait for "more research". In this study, the term belief in climate change is measured in two ways: first, as strength of agreement with three statements about climate change (occurrence, severity of the problem, and causes), and second, as perception of climate change risk.

The dependent variable for this study is preference for immediate action on climate change, and the major variables of interest operationalize beliefs about climate change, including risk perception. The primary research goal is to determine which individual differences (e.g., climate change beliefs, socio-demographic characteristics) are associated with a preference for immediate action. In particular, this study seeks to assess whether increasing the strength of conviction about climate change leads to an increase in the support for action. 


\section{Background}

Theories of behavioral intentions $[8,12,13]$ suggest that awareness of causes and consequences are required to motivate action. While additional factors such as values and worldviews, discussed below, play a role in views about climate change, strength of belief seems rooted in understanding climate change and associated risks. With respect to climate science, the likelihood of preferring immediate action has been associated with an awareness of the causes of climate change and the severity of its consequences $[9,12,14-18]$. Support for climate action is also related to how individuals perceive the risks from climate change [14,15,18-20], with higher risk perceptions associated with greater support for immediate action. Together, this study treats these constructs jointly as belief in climate change, which constitutes the major variable of interest.

Previous research also suggests that belief is not binary; rather, it falls along a continuum from denial to conviction [1]. The extent of beliefs, in turn, is related to behavioral intentions. Two studies have shown that the extent to which an individual believes in climate change is positively correlated to the amount of adaptive measures undertaken by farmers [21] and forest owners [22]. Also with respect to voluntary behavior, Aitken, Chapman, and McClure [23] find that perceptions of risk and human influence on climate change were significant predictors of New Zealanders taking action. Our study extends this literature in two ways: first, by examining a population in the U.S., where Aitken, et al. [23] note there is a greater contingent of climate denialists; and second, by using a more general measure of preference for "immediate action" on climate change, rather than focusing on voluntary measures.

To directly examine the association between climate change beliefs and preference for immediate action, this analysis controls for several additional factors identified as relevant in the literature. Broadly, these include cultural worldviews, pro-environmental attitudes, political party affiliation, and socio-demographic information. The cultural worldviews that individuals hold have been found to be important determinants of their action preference [20,24,25]. Cultural cognition theory posits that individuals perceive risks based upon shared value systems, which can be identified as distinct patterns of social relations [26]. Three cultural worldviews are used in the present study: individualism, hierarchy, and egalitarianism. Individualists value freedom from regulation and tend to trust market outcomes. Adherents of hierarchy prefer stability in social relations and feel threatened by deviations from the social order. Egalitarians value just distributions of wealth and opportunity and are concerned with how social order disadvantages certain groups. We expect those adhering to individualism and hierarchy to oppose immediate climate change action, as climate policies may be perceived as threatening to free markets and the social order more generally [27]. Egalitarianism, on the other hand, has been shown to be positively correlated with support for national and international climate policies [24].

A general pro-environmental orientation has been shown to positively predict preference for action on climate change $[9,12,14]$. Political affiliation is also relevant; public opinion on climate change [28,29], beliefs about climate change [30,31], and support for public policies [4] have all been found to vary by party identification, where Republicans show less support for action on climate change than Democrats and Independents. Finally, women, younger individuals, those with higher incomes, and more highly educated individuals are expected to be more supportive of action on climate change $[8,9,16,18]$. There are other covariates that we have not included for lack of salience in our review of the literature, such as spiritual beliefs, although such constructs may be relevant in similar strains of research. 


\section{Methods}

\subsection{Survey Site}

This study investigates public opinion data gathered via telephone survey from residents of the State of Indiana. The Indiana sampling frame provides two theoretical benefits. First, in the absence of national action, the states have taken a lead role in advancing climate policy in the U.S. [32-34]; and the future of climate policy may well depend on the behavior of sub-national governments [35]. Therefore, it is important to investigate public attitudes within states, especially as they relate to support for action on climate change. The literature is currently expanding to include a focus on state-level public opinion about climate change; for example, recent work reports on climate change attitudes in the State of Ohio [36]. Second, Indiana is a coal-reliant, Midwestern state, where reluctance to act on climate change may be particularly pronounced and where leading politicians from both parties have resisted both state and national climate policies [37,38]. If high levels of public support are necessary for action on climate change, it should be especially revealing to study the nature of public support in a state dominated by skeptical leaders.

Both citizens and politicians in Indiana are typically more conservative than the nation as a whole [39]. Indiana's economy, with a mixture of agriculture, mining, and manufacturing, is dependent on businesses that emit GHG; and Indiana ranks seventh in the U.S. in coal production and first in the proportion of electricity produced from coal [40]. Indiana is one of only six of states that have not adopted any of the following (as of November 2013): GHG emissions targets, GHG emission caps for electricity production, climate action or adaptation plans, climate change commissions or advisory groups, participation in regional climate initiatives, or GHG reporting registries [41,42].

Policymakers from Indiana also played an influential role in limiting national climate policy. During 2008-2010, there were two major initiatives for national climate pricing legislation informally known as the Kerry-Boxer and Waxman-Markey bills, due to their legislative sponsors. Having once been a legislative priority of President Barack Obama, these bills faltered in the Senate after Democrats from key Midwestern states (including Indiana, Michigan, Missouri, Nebraska, Ohio and Wisconsin) expressed their unwillingness to support the initiatives.

Given these facts, it is apparent that Indiana is both a key player and reluctant to support action on climate change; this study aims to investigate why this is so. Inaction may be due to the prevalence of climate skeptics (i.e., those who may be uncertain of the meaning of the observational data and its implications and impacts), or it may be the case that Indiana residents, though accepting of the conclusions drawn by climate change science, are not motivated to support immediate action. Thus, this survey provides an opportunity to understand the dynamics of public opinion at the sub-national level.

\subsection{Survey Administration}

Following pre-testing and instrument refinement, the survey was administered by telephone between 28 June and 3 August 2011. Respondents were selected through random digit dialing procedures that ensured adequate sampling of numbers for both mobile phones and landlines. Only Indiana residents who were 18 years of age and older were eligible to partake in the study. To encourage participation, respondents were given a $\$ 5$ payment for completing the survey. Typical interviews lasted about 
$20 \mathrm{~min}$, and the response rate for the survey was 18.2\% [43]. The initial sample size was 1001 respondents. The final sample size is 832 and includes only those respondents who answering all of the survey questions. The characteristics of dropped respondents show no significant differences except for age, where older respondents were more likely not to have completed the survey.

\subsection{Survey Questions and Coding}

The survey asked respondents about key concepts related to climate change beliefs, risk perception, preference for action on climate change, and demographic characteristics. Questions of interest are described below [44].

\subsubsection{Action on Climate Change}

Respondents were asked to indicate which of three statements most closely matched their opinions about climate change: (a) Immediate action is necessary to reduce climate change; (b) More research is necessary before we take any action to reduce climate change; and (c) No action should be taken to reduce climate change. Data analysis revealed few significant differences between respondents who preferred more research or no action. These options were collapsed into a dichotomous variable coded 1 for immediate action and 0 for anything else.

\subsubsection{Beliefs about Climate Change}

Respondents were asked to indicate their level of agreement on a four-point scale ("strongly agree", "somewhat agree", "somewhat disagree", and "strongly disagree") with three statements about climate change: (a) Climate change is currently occurring; (b) Climate change has been established as a serious problem; and (c) Human activities are contributing to climate change. Responses were coded on a scale from 1 (strongly disagree) to 4 (strongly agree). Respondents were also asked to rate the risk that climate change poses to American society on a five-point scale from 1 (no risk) to 5 (very large risk). The responses to all four of these questions were highly correlated, with a standardized Cronbach's alpha of 0.87 .

Although these four variables are measured on two different scales-one scale for the agreement questions and another for risk - the high correlation suggests that they are capturing a general construct related to beliefs about climate change; thus they were combined into a single composite climate change belief score. First, risk perception ratings were rescaled to be between 1 (no risk) and 4 (very large risk) from the previous scale range of 1 to 5. Second, the arithmetic mean of the responses to all four questions was calculated. The resulting composite score ranged from 1 (analogous to disbelieving in climate change and perceiving no risk) to 4 (analogous to strongly agreeing with climate change and perceiving a very large risk). This composite score was treated as a continuous variable.

\subsubsection{Environmentalism}

Respondents were asked three questions that aimed to elicit their attitudes toward the environment: (a) whether they were a dues-paying member of an environmental organization; (b) whether the environment or the economy should be given higher priority; and (c) whether they believed that land is fragile and should be treated with care or if the land is resilient and recovers from damages quickly. 


\subsubsection{Cultural Worldviews}

The survey employed a modified version of the cultural worldviews scale created by Ellis and Thompson [45]. Due to length constraints, only six of the nine original questions were used, with two statements corresponding to each worldview: individualism (e.g., "Society would be better off if there was much less government regulation of business"); hierarchy (e.g., "One of the problems with people today is that they challenge authority too often"); and egalitarianism (e.g., "The world would be a better place if its wealth were divided more equally among nations"). Respondents were asked to indicate their level of agreement on a four-point scale to each of the six questions; responses were averaged for each worldview to create three scores [46]. These responses ranged from 1 (strongly disagree) to 4 (strongly agree).

\section{Results}

\subsection{Sample Representativeness}

To assess the representativeness of the sample, the socio-demographic characteristics of the respondents are compared to the populations of Indiana and the U.S. using data from the U.S. Census [47]. As shown in Table 1, the sample is more female, older, and more educated than the population of Indiana, though the income distribution is similar. After weighting on demographic characteristics and location of residence within Indiana, the characteristics of the respondent sample more closely reflect the larger state population in terms of gender, age, and education, but with slightly lower incomes. The mean age in the weighted sample was 48 . Weighted data are used for all subsequent analyses.

The population of Indiana has a similar demographic profile to the U.S. as a whole, as shown in Table 1. The state reflects the national characteristics in terms of male-to-female ratio and age structure. With respect to sociological variables, the population of Indiana has a higher proportion of people with a high school degree, a lower proportion with any level of college education, and a lower proportion of high-income families. Indiana and the U.S. have similar employment and unemployment rates as well as similar occupational profiles; the most notable exception is that Indiana has a higher proportion of its workforce employed in the production, transportation, and material moving sector (17.5\% in Indiana vs. $12.1 \%$ nationwide [47]).

Table 1. Comparison of demographic characteristics across survey sample and the populations of Indiana and the U.S. (percentages).

\begin{tabular}{lcccc}
\hline Characteristic & Sample & Weighted Sample & Indiana Population & U.S. Population \\
\hline Sex & & & & \\
\hline Male & 44.7 & 49.7 & 48.5 & 48.5 \\
\hline Age & & & & \\
\hline $18-24$ & 3.7 & 8.3 & 12.6 & 13.2 \\
$25-34$ & 9.3 & 17.8 & 17.6 & 17.4 \\
$35-44$ & 10.5 & 18.5 & 16.9 & 17.9 \\
$45-54$ & 17.6 & 20.8 & 19.3 & 19.2 \\
$55-64$ & 25.1 & 16.1 & 15.7 & 15.3 \\
65 and older & 33.9 & 18.5 & 17.9 & 17.0 \\
\hline
\end{tabular}


Table 1. Cont.

\begin{tabular}{lcccc}
\hline \multicolumn{1}{c}{ Characteristic } & Sample & Weighted Sample & Indiana Population & U.S. Population \\
\hline Education & & & & \\
\hline Less than high school & 6.0 & 10.0 & 11.5 & 14.7 \\
High school degree & 31.7 & 38.5 & 45.7 & 28.4 \\
Some college or AA degree & 25.6 & 23.8 & 22.0 & 28.9 \\
BA degree or higher & 34.0 & 24.0 & 20.7 & 28.0 \\
\hline Family income & & & & \\
\hline Less than $\$ 24,999$ & 25.5 & 25.9 & 24.5 & 23.5 \\
\$25,000-\$49,999 & 31.4 & 32.8 & 27.6 & 18.6 \\
\$50,000-\$74,999 & 19.8 & 18.6 & 20.1 & 12.3 \\
\$75,000-\$99,999 & 11.7 & 12.1 & 12.5 & 20.9 \\
\$100,000 and higher & 11.7 & 10.7 & 15.3 & \\
\hline
\end{tabular}

\subsection{Elicited Attitudes and Characteristics}

When asked for their opinion on mitigating climate change, only a minority supported immediate action to reduce climate change: Thirty-eight percent preferred immediate action; $50 \%$ preferred more research; and 12\% responded that no action should be taken to reduce climate change. While this might lead to the expectation of ambivalence among the respondents about the reality or dangers of climate change, the data show a different story. A large majority of respondents agreed, to some extent, with the statements about climate change (see Figure 1). Eighty-five percent of respondents agreed that climate change is occurring, $71 \%$ agreed that it has been established as a serious problem, and $80 \%$ agreed that human activities contribute to climate change.

Likewise, over half of the respondents perceived climate change as posing a serious risk to American society. On a five-point scale, $28 \%$ of respondents rated climate change as a very large risk, $23 \%$ as a large risk, $24 \%$ as somewhat of a risk, $15 \%$ as a low risk, and $10 \%$ as not a risk at all. These two measures, beliefs about climate change and risk perception, form the basis for the composite climate belief score. The average respondent expressed moderate beliefs and perception of risk about climate change. On a scale of 1 to 4 , the mean of the composite climate belief score was $3.08(S D=0.041)$, and the median score was 3.2 with an interquartile range of 2.6-3.8.

The measures for the control variables give no clear indication of the attitudes of the respondents with respect to climate change. For environmental indicators, the respondents were approximately split on which should be given a higher priority: the environment $(52 \%)$ or the economy (48\%). A large majority (84\%) believed that the land is fragile, and $11 \%$ were members of an environmental organization. Scores on questions about cultural worldviews showed, on average, that respondents generally fell in the range of somewhat agreeing with statements representative of each of the three worldviews in this survey. On a scale from 1 to 4 (strongly disagreeing to strongly agreeing), the mean score for individualism was $2.97(S D=0.039)$, for egalitarianism $2.75(S D=0.046)$, and for hierarchy $2.86(S D=0.043)$. As for political party affiliation, approximately $28 \%$ of the respondents identified as Republicans, 33\% as Democrats, and 39\% as Independents, proportions broadly reflective of nationwide trends [48]. 
Figure 1. Respondents' responses to statements about climate change science.

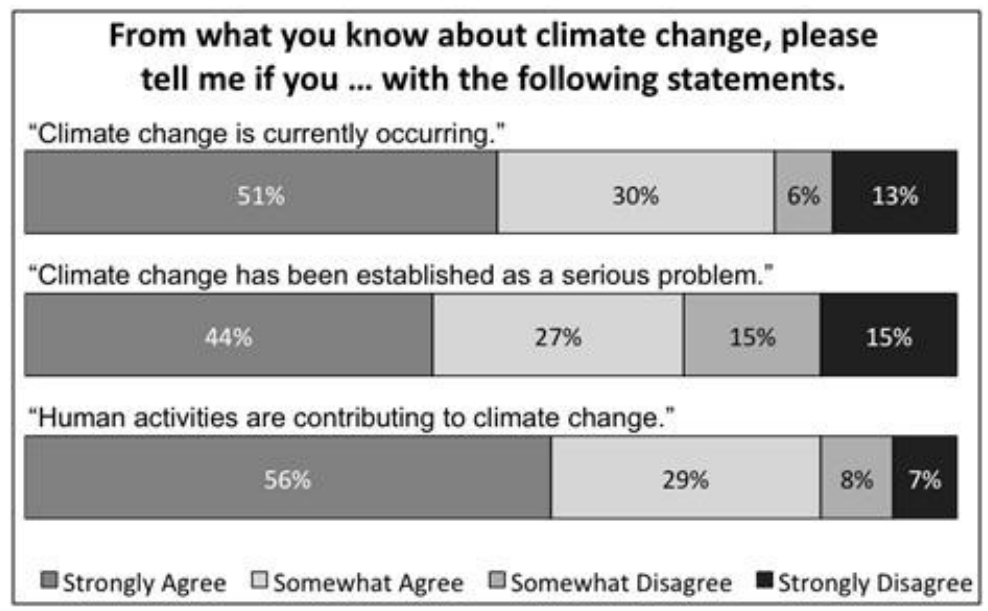

\subsection{Data Analysis}

The data are analyzed using a probit regression [49,50], with success defined as preferring immediate action on climate change. All independent variables are dichotomous except for age, the composite climate change belief score, and the three measures of cultural worldviews [51]. The results in Table 2 show the probit parameter estimates. Positive parameter estimates indicate that the probability of preferring immediate action is higher than the probability of preferring either more research or no action. Typical measures of goodness of fit are not appropriate for analyses of weighted data; instead, the model correctly predicts $85 \%$ of the observations with a preference for immediate action and $71 \%$ of the observations with a preference for some other option.

Table 2. Probit regression on preference for action on climate change.

\begin{tabular}{lc}
\hline \multicolumn{1}{c}{ Parameters } & "Immediate action" vs. Anything else \\
\hline Male & 0.167 \\
& $(0.160)$ \\
\hline Age & -0.007 \\
& $(0.005)$ \\
\hline Income 100k+ & $0.977 * * *$ \\
& $(0.231)$ \\
\hline College & 0.102 \\
& $(0.201)$ \\
\hline Composite climate change belief score & $1.320 * * *$ \\
& $(0.161)$ \\
\hline Individualism & -0.152 \\
& $(0.113)$ \\
\hline Egalitarianism & 0.172 \\
& $(0.094)$ \\
\hline Hierarchy & $-0.287 * *$ \\
& $(0.104)$ \\
\hline Environment higher priority than economy & 0.196 \\
& $(0.159)$ \\
\hline
\end{tabular}


Table 2. Cont.

\begin{tabular}{lc}
\hline \multicolumn{1}{c}{ Parameters } & "Immediate action" vs. Anything else \\
\hline Land is Fragile & 0.138 \\
& $(0.265)$ \\
\hline Environmental group member & 0.239 \\
& $(0.277)$ \\
\hline Republican & -0.111 \\
& $(0.204)$ \\
\hline Democrat & 0.277 \\
& $(0.192)$ \\
\hline Constant & $-4.048 * * *$ \\
& $(0.764)$ \\
\hline
\end{tabular}

Note: Probit parameter estimates with standard errors in parentheses. Reference category for political party is Independents. $N=832$. $* p<0.05,{ }^{* *} p<0.01,{ }^{* * *} p<0.001$.

\subsubsection{Socio-Demographic Characteristics}

Gender, age, and education are not significant predictors of preference for action. The highest income category is significant $(p<0.001)$ and substantively important. Holding all other variables at their mean values, respondents from high-income families were $35 \%$ more likely to prefer immediate action to any other response.

\subsubsection{Beliefs about Climate Change}

The composite climate change belief score is a significant $(p<0.001)$ predictor of the preference for immediate action relative to more research or no action. The association is best illustrated by showing the predicted probabilities for each response over the entire range of the composite belief scores (Figure 2). Holding all other variables at their mean values, support for immediate action is positively associated with the strength of belief in climate change, as expected. Surprisingly, the relationship between support for immediate action and belief in climate change is highly non-linear. Over the range of composite belief scores from 1 to 2, which imply strong to limited disbelief, support for immediate action is close to zero. Support for immediate action rises slowly as the composite scores rise from 2 to 3, the range from limited disbelief to limited belief. Between 3 and 4, as belief rises from somewhat to strong, support for immediate action rises substantially. Immediate action is the most likely response for composite belief scores above 3.6. At the highest possible composite belief score, 4 , the predicted probability of preferring immediate action on climate change is $75 \%$; among respondents with this score, $73 \%$ actually indicated a preference for immediate action. The accuracy of the model is further illustrated by plotting the actual mean level of support by composite belief score quintiles [52]. 
Figure 2. The association between composite climate change belief score and the predicted probability of climate action preference. By comparison, the composite climate change belief score was broken down by quintiles, and the actual percentage of each quintile preferring immediate action is also shown.

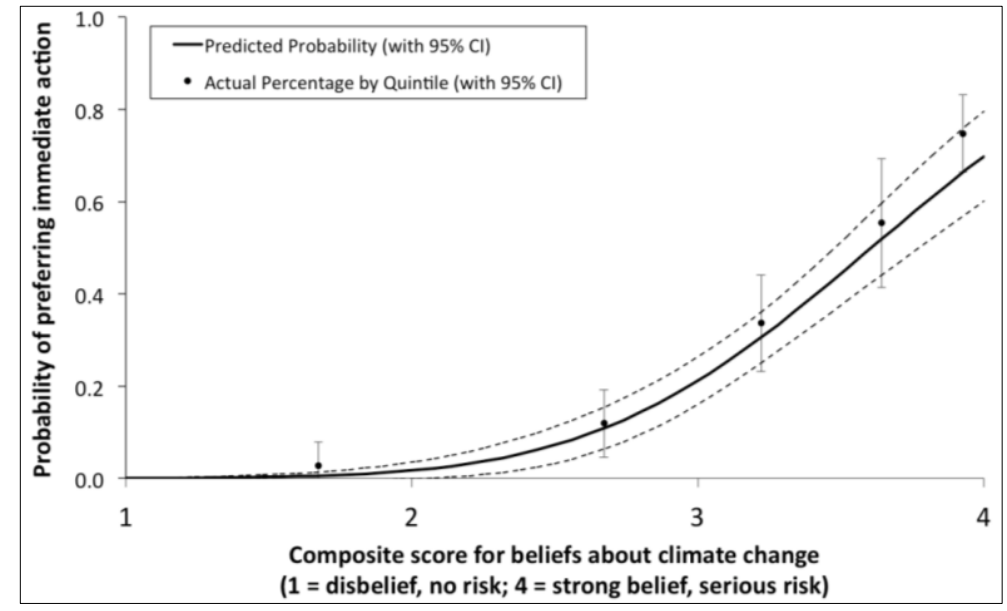

\subsubsection{Cultural Worldviews}

Only hierarchy was statistically significant in the probit regression $(p=0.006)$. Holding all other variables at their mean values, and over the range of possible responses, the predicted probability of preferring immediate action declines linearly from 42\% (low agreement with hierarchy) to $14 \%$ (high agreement).

\subsubsection{Other Control Variables}

Neither indicators of environmentalism nor party affiliation were significant predictors of the preference for immediate action on climate change, though the valences of these parameter estimates were in the expected direction.

\section{Discussion}

\subsection{Sample Description}

When comparing results from this survey of Indiana residents to similar questions asked in nationwide surveys, there are some similar patterns for preferences for action on climate change and similar levels of agreement with statements about climate change. A nationwide survey administered two years prior to the Indiana survey yielded different results when respondents were offered an additional response option of "some action": $23 \%$ preferred immediate action; $31 \%$ preferred some action; $29 \%$ preferred more research; and 12\% responded that concern over global warming was unwarranted [53]. Since the response set from the current survey excludes some action, the results of the two surveys cannot be directly compared. However, the net effect of this exclusion may be that immediate action respondents in the Indiana survey include the respondents who would otherwise prefer some action had they been given the national survey. The Indiana response categories, which 
exclude the "some action" concept, may more accurately reflect the sense of urgency that is the focus of this investigation.

The questions asking about agreement with statements about climate change did not provide respondents with the option of responding with "unsure" or "don't know." Not including these options suggests that some respondents of the Indiana sample who are unsure of, or unwilling to agree to, statements about climate change may actually have reservations better captured by the centrist responses: somewhat agree or somewhat disagree. Therefore some of these seemingly moderate "somewhat" responses may actually have at least two possible interpretations: either the respondents have a firm grasp of climate science, which leads them to only somewhat support the statements about climate change; or respondents have a weak understanding of climate science, which limits the extent to which they are willing to strongly agree or disagree with the statements.

In terms of belief in climate change, the representative Indiana sample showed results that are similar to national samples, as a recent nationwide Gallup survey found 55\% of respondents agreeing that global warming is occurring, $38 \%$ that it is a serious threat, and $52 \%$ citing human activities as a cause [54]. The proportions of respondents agreeing with climate change in these national samples roughly correspond to the proportions that strongly agreed with each statement in the Indiana sample. Combining the respondents who strongly or somewhat agree with climate change statements, the results suggest higher levels of general agreement with statements about climate change in Indiana than nationwide polls might suggest, but this may be attributable to the broader set of response options, specifically, the option to somewhat agree. These results certainly do not support the hypothesis that the dominant view of Indiana residents with regard to climate change is one of climate skepticism (as defined earlier).

\subsection{Preference for Action on Climate Change}

The main finding from the probit regression is that the composite climate change belief score has a large, significant, and positive association with the probability of preferring immediate action. The positive relationship between climate change beliefs and preference for immediate action shown in the results of this study confirm previous findings [12,14-16,18]. However the newly discovered non-linear relationship between climate change beliefs and preference for immediate action, with the steep increase in preference at the point where beliefs shift from moderate to strong, directs attention to where the climate policy community should focus their efforts to spur national action. It should also be noted that the majority (64\%) of the sample had composite climate change belief scores below 3.6 (on a scale from 1-4), the level beyond which support for immediate action is the most likely preference. The minority position of strong believers is a plausible explanation for lack of action on climate change, a line of inquiry discussed further in the conclusion. Lower levels of belief may reflect greater uncertainty about the nature and risks from climate change, and more generally, people often delay preparation for natural disasters until uncertainty is resolved [55]. This confirms that support for immediate climate action is associated not only with whether an individual believes in climate change but also how strong that belief is. This analysis is, to our knowledge, the first to emphasize the substantive importance of degree of belief among the larger public, especially the strength of support among those with the highest levels of belief. 
Few other variables were significant predictors in the regression results. In terms of substantive significance, high family income was highly predictive, indicating that the respondents from the highest income category are more willing to support immediate action over the other options. One explanation for this finding is that income may be a proxy for post-materialist values, which are theoretically linked with stronger environmental concern [15,56,57]. Contrary to previous research on cultural cognition theory, which showed that worldviews are determinants of action preference [15,24,25], only agreement with a hierarchal cultural worldview was found to be a statistically significant predictor, indicating a lower probability of preferring immediate action, as expected.

In general, the lack of significance in many of the parameter estimates suggests that the composite climate change belief score is capturing much of the explanatory power in the model. This pattern of results is consistent with the evidence from Vainio and Paloniemi [57], who show that beliefs about climate change mediate other factors associated with support for action on climate change (see also Dietz, et al. [16]). While many of the control variables are fixed or stable over time, their lack of significance (and the primacy of the composite belief score) has provocative implications for risk communication and climate education.

\section{Conclusions}

This study provides evidence of a strong association between belief in climate change and support for immediate action on climate change. Moreover, beliefs about climate change are shown to have a non-linear relationship with the preference for immediate action. The probability of supporting immediate action is much higher among those who strongly believe in climate change than among those who are more moderate.

Before proceeding with the implications of this relationship, it is important to note the limitations of this study. The associations found here do not necessarily define a causal relationship between strength of beliefs and support for immediate action. First, a public opinion survey can only gauge statements of support rather than reveal true intentions; such statements may have limited predictive power as indicators of behavioral intentions. Second, beliefs about climate change may be mediating other factors related to support for immediate action, or, third, respondents may arrive at their action preference first and then temper their views; for example, those who prefer more research may be motivated to rationalize what their current lifestyle in Indiana represents.

Fourth, the value-action gap theory poses several barriers between environmental concern and pro-environmental behavior, including individuality, responsibility, and practicality [7]. If accurate, strong beliefs about climate change are necessary but insufficient conditions for supporting concrete action. With respect to individuality, consumers are less willing to engage in high-cost tactics for mitigating climate change [58], and policies that target individuals enjoy lower support than policies that affect firms [1]. Thus, those who prefer more research over immediate action may do so for reasons that are unrelated to beliefs in climate change or climate risk perception (e.g., they may fear the potential impacts of immediate action on the economy of Indiana or they may resist lifestyle changes). While this survey sought to avoid focusing on any particular action or policy, previous work shows that support for specific mitigation efforts and climate policies, is dependent upon perceptions 
of efficacy $[59,60]$. Together, these limitations provide further direction for future research into whether there is a causal link between strength of belief in climate change and support for immediate action.

The implications of such a causal relationship are especially relevant to the field of risk communication. More specifically, this study raises the hypothesis that education about the consequences of climate change specifically aimed at those who express a moderate level of belief in climate change may have potentially large payoffs in increasing public support for immediate action. Previous research shows additional evidence that this hypothesis is plausible.

The Six Americas analysis of public opinions on climate change [1] has several parallels to this line of inquiry. This study situates respondents on a continuum, from those with the lowest levels of belief in climate change, labeled the "dismissive", through the highest levels, the "alarmed"; this continuum intrinsically links agreement with statements about climate science to both concern and motivation about climate change. Three intermediate groups, the "disengaged", "cautious", and "concerned", are most relevant to the hypothesis that strengthening beliefs increases support for immediate action. Their responses to three particular questions are suggestive that their views are malleable. First, majorities of the cautious and the disengaged and about a third of the concerned reported that they felt uninformed about climate change. Second, these segments also agreed in large proportions that they needed more information before they could make up their minds on the issue. Third, and most importantly, majorities of the cautious and the disengaged and about a third of the concerned agreed to some extent that they could easily change their minds. Thus, the Six Americas survey provides strong, independent indications that climate change education focusing on the intermediate groups may increase preference for immediate action.

Our study also marks a departure from the literature on climate change communication and education. Previous work on the information deficit model has shown that the dissemination of information about climate change is neither necessary nor sufficient for motivating preferences on action $[25,61,62]$. Indeed, greater awareness of climate science can lead to greater polarization if information is used as fodder for motivated reasoning [63]; converting climate skeptics based upon enhancing their understanding of climate change is highly unlikely, since their attitudes may be guided by ideology rather than ignorance or misunderstanding [64,65]. These problems lead some researchers to focus on the means of communication $[61,63,66,67]$. Here we focus on a specific audience that of Indiana residents, to study support for immediate action. It may not be necessary to convert the skeptics; rather, the greatest increase in support for immediate action may come from strengthening the composite beliefs of those who already moderately agree that climate change is occurring.

Further work is also required in order to determine how widespread strong beliefs must be before sufficient numbers of the public adopt voluntary behaviors and support political action to the point where it comes to fruition. Even in the absence of large majority support, President Obama and some state legislatures continue to promulgate climate and energy policies. These policies, however, may be grounded in concerns over energy security rather than climate change, and their stringency may reflect low salience or popularity among the electorate. Public support may make policies that more directly and effectively address climate change more tractable. Elected politicians may be particularly responsive to individuals with strongly held beliefs, even when those beliefs are not shared by the median voter [68,69]; thus there may also be a specific threshold at which policy makers begin to acknowledge and respond to public support for various climate policies. Current surveys in the U.S. 
show that this level of support may be high, but this study provides a possible explanation as to why it has not yet arrived.

\section{Acknowledgments}

Funding for this study was provided by the School of Public and Environmental Affairs at Indiana University Bloomington. We also thank David Krantz for valuable feedback, Princeton Survey Research Associates and Braun Research for helpful suggestions during survey development and for administering the survey, and survey respondents for their time.

\section{Conflicts of Interest}

The authors declare no conflict of interest.

\section{References and Notes}

1. Leiserowitz, A.; Maibach, E.; Roser-Renouf, C.; Smith, N. Global Warming's Six Americas in May 2011. Available online: http://environment.yale.edu/climate-communication/files/ SixAmericasMay2011.pdf (accessed on 27 October 2013).

2. Hamilton, L.C. Education, politics and opinions about climate change evidence for interaction effects. Clim. Change 2010, 104, 231-242.

3. Marquart-Pyatt, S.T.; Shwom, R.L.; Dietz, T.; Dunlap, R.E.; Kaplowitz, S.A.; McCright, A.M.; Zahran, S. Understanding public opinion on climate change: A call for research. Environment 2011, 53, 38-42.

4. Brewer, T.L. US public opinion on climate change issues: Implications for consensus-building and policymaking. Clim. Pol. 2005, 4, 359-376.

5. Krosnick, J.A. The Climate Majority. The New York Times, 8 June 2010.

6. Leiserowitz, A.; Maibach, E.; Roser-Renouf, C.; Hmielowski, J.D. Climate Change in the American Mind: Public Support for Climate \& Energy Policies in March 2012; Yale Project on Climate Change Communication: New Haven, CT, USA, 2012.

7. Blake, J. Overcoming the "value-action gap" in environmental policy: Tensions between national policy and local experience. Local Environ. 1999, 4, 257-278.

8. Kollmuss, A.; Agyeman, J. Mind the gap: Why do people act environmentally and what are the barriers to pro-environmental behavior? Environ. Educ. Res. 2002, 8, 239-260.

9. O'Connor, R.E.; Bord, R.J.; Yarnal, B.; Wiefek, N. Who wants to reduce greenhouse gas emissions? Soc. Sci. Q. 2002, 83, 1-17.

10. Bain, P.G.; Hornsey, M.J.; Bongiorno, R.; Jeffries, C. Promoting pro-environmental action in climate change deniers. Nat. Clim. Change 2012, 2, 600-603.

11. Hardisty, D.J.; Johnson, E.J.; Weber, E.U. A dirty word or a dirty world? Attribute framing, political affiliation, and query theory. Psychol. Sci. 2010, 21, 86-92.

12. Stern, P.C.; Dietz, T.; Abel, T.; Guagnano, G.A.; Kalof, L. A value-belief-norm theory of support for social movements: The case of environmentalism. Hum. Ecol. Rev. 1999, 6, 81-98. 
13. Tikir, A.; Lehmann, B. Climate change, theory of planned behavior and values: A structural equation model with mediation analysis. Clim. Change 2010, 104, 389-402.

14. Bord, R.J.; O'Connor, R.E.; Fisher, A. In what sense does the public need to understand global climate change? Public Underst. Sci. 2000, 9, 205-218.

15. Brody, S.; Grover, H.; Vedlitz, A. Examining the willingness of Americans to alter behaviour to mitigate climate change. Clim. Pol. 2012, 12, 1-22.

16. Dietz, T.; Dan, A.; Shwom, R. Support for climate change policy: Social psychological and social structural influences. Rural Sociol. 2007, 72, 185-214.

17. Markowitz, E.M. Is climate change an ethical issue? Examining young adults' beliefs about climate and morality. Clim. Change 2012, 114, 479-495.

18. O’Connor, R.E.; Bord, R.J.; Fisher, A. Risk perceptions, general environmental beliefs, and willingness to address climate change. Risk Anal. 1999, 19, 461-471.

19. Kellstedt, P.M.; Zahran, S.; Vedlitz, A. Personal efficacy, the information environment, and attitudes toward global warming and climate change in the United States. Risk Anal. 2008, 28, 113-126.

20. Zahran, S.; Brody, S.D.; Grover, H.; Vedlitz, A. Climate change vulnerability and policy support. Soc. Nat. Resour. 2006, 19, 771-789.

21. Weber, E.U. Perception and Expectation of Climate Change: Precondition for Economic and Technological Adaptation. In Psychological Perspectives to Environmental and Ethical Issues in Management; Bazerman, M., Messick, D., Tenbrunsel, A., Wade-Benzoni, K., Eds.; Jossey-Bass: San Francisco, CA, USA, 1997; pp. 314-341.

22. Blennow, K.; Persson, J. Climate change: Motivation for taking measure to adapt. Glob. Environ. Change 2009, 19, 100-104.

23. Aitken, C.; Chapman, R.; McClure, J. Climate change, powerlessness and the commons dilemma: Assessing New Zealanders' preparedness to act. Glob. Environ. Change 2011, 21, 752-760.

24. Leiserowitz, A. Climate change risk perception and policy preferences: The role of affect, imagery, and values. Clim. Change 2006, 77, 45-72.

25. Shwom, R.; Bidwell, D.; Dan, A.; Dietz, T. Understanding U.S. public support for domestic climate change policies. Glob. Environ. Change 2010, 20, 472-482.

26. Wildavsky, A.; Dake, K. Theories of risk perception: Who fears what and why? Daedalus 1990, 119, 41-60.

27. Kahan, D.M.; Peters, E.; Wittlin, M.; Slovic, P.; Ouellette, L.L.; Braman, D.; Mandel, G. The polarizing impact of science literacy and numeracy on perceived climate change risks. Nat. Clim. Change 2012, 2, 732-735.

28. Brulle, R.J.; Carmichael, J.; Jenkins, J.C. Shifting public opinion on climate change: An empirical assessment of factors influencing concern over climate change in the U.S., 2002-2010. Clim. Change 2012, doi:10.1007/s10584-012-0403-y.

29. Dunlap, R.E.; McCright, A.M. A widening gap: Republican and democratic views on climate change. Environment 2008, 50, 26-35.

30. Borick, C.P.; Rabe, B.G. A reason to believe: Examining the factors that determine individual views on global warming. Soc. Sci. Q. 2010, 91, 777-800. 
31. McCright, A.M.; Dunlap, R.E. Cool dudes: The denial of climate change among conservative white males in the United States. Glob. Environ. Change 2011, 21, 1163-1172.

32. Lutsey, N.; Sperling, D. America's bottom-up climate change mitigation policy. Energy Policy 2008, 36, 673-685.

33. Rabe, B.G. Statehouse and Greenhouse: The Emerging Politics of American Climate Change Policy; Brookings Institution Press: Washington, DC, USA, 2004.

34. Rabe, B.G. States on steroids: The intergovernmental odyssey of American climate policy. Rev. Policy Res. 2008, 25, 105-128.

35. Burke, B.; Ferguson, M. Going alone or moving together: Canadian and American middle tier strategies on climate change. Publius 2010, 40, 436-459.

36. Leiserowitz, A.; Feinberg, G.; Howe, P.; Rosenthal, S. Climate Change in the Ohioan Mind; Yale Project on Climate Change Communication: New Haven, CT, USA, 2013.

37. Daniels, M. Indiana Says "No Thanks" to Cap and Trade. Available online: http://online.wsj.com/ news/articles/SB124234844782222081 (accessed on 27 October 2013).

38. Graham, J.D.; Stidvent, V.V. Presidential Policy Making in a Polarized Era: Comparing the George W. Bush and Obama Administrations. In Proceedings of the Change in the White House? Comparing the Presidencies of George W. Bush and Barack Obama, Hempstead, NY, USA, 19 April 2012.

39. Berry, W.D.; Ringquist, E.J.; Fording, R.C.; Hanson, R.L. Measuring citizen and government ideology in the American states, 1960-93. Am. J. Pol. Sci. 1998, 42, 327-348.

40. Energy Information Administration Coal Production and Number of Mines. Available online: http://www.eia.gov/coal/data.cfm\#production (accessed on 27 October 2013).

41. Center for Climate and Energy Solutions Indiana. Available online: http://www.c2es.org/ states-regions/states/Indiana (accessed on 27 October 2013).

42. NC Solar Center Indiana Incentives for Renewables and Efficiency. Available online: http://www.dsireusa.org/library/includes/map2.cfm?CurrentPageID=1\&State=IN\&RE=1\&EE=1 (accessed on 27 October 2013).

43. As calculated according to the formula for "Response Rate 3", in the American Association for Public Opinion Research (AAPOR). Standard Definitions: Final Dispositions of Case Codes and Outcome rates for Surveys; AAPOR: Lenexa, KS, USA, 2011; pp. 44-45.

44. The full survey instrument is available from the corresponding author.

45. Ellis, R.J.; Thompson, F. Culture and the environment in the Pacific Northwest. Am. Polit. Sci. Rev. 1997, 91, 885-897.

46. Pairwise standardized Cronbach's alpha for each worldview were comparable to those reported in Ellis and Thompson [45] (Table B-3).

47. U.S. Census 2006-2010 American Community Survey 5-Year Estimates. Available online: http://factfinder2.census.gov/ (accessed on 27 October 2013).

48. Jones, J. Record-High $40 \%$ of Americans Identify as Independents in '11. Gallup Poll, 10 January 2012.

49. Data analysis conducted using Stata 11.2, following post-estimation procedures outlined in Long, J.S. Nominal Outcomes: Multinomial Logit and Related Models. In Regression Models for 
Categorical and limIted Dependent Variables; Sage Publications: Thousand Oaks, CA, USA, 1997; pp. 148-186.

50. Predicted probabilities are calculated with the SPost module for Stata, explained in Long, J.S.; Freese, J. Regression Models for Categorical Dependent Variables Using Stata, 2nd ed.; Stata Press: College Station, TX, USA, 2006.

51. Our results are robust to alternative model specifications using additional income and education categories.

52. The non-linear relationship was robust to alternative predictions with dummies set at their extreme values and continuous variables set at the extremes of their interquartile range. The exception was the indicator for high family income, which has a pronounced effect on predicted probabilities; this is likely due to its large substantive significance relative to other parameter estimates.

53. Hart, P.; McInturff, W. NBC News/Wall Street Journal Survey. Available online: http://msnbcmedia.msn.com/i/MSNBC/Sections/NEWS/A_Politics/_Politics_Today_Stories_Teases/ 091215_NBC_WSJ_Poll.pdf (accessed on 27 October 2013).

54. Jones, J.; Saad, L. Global Warming. In Gallup Poll Social Series: Environment; Gallup Press: Washington, DC, USA, 2012.

55. Paton, D.; McClure, J.; Bürgelt, P.T. Natural Hazard Resilience: The Role of Individual and Household Preparedness. In Disaster Resilience: An Integrated Approach; Charles C. Thomas Publisher: Springfield, IL, USA, 2006; pp. 105-127.

56. Inglehart, R. Public support for environmental protection: Objective problems and subjective values in 43 societies. PS: Polit. Sci. Polit. 1995, 28, 57-72.

57. Vainio, A.; Paloniemi, R. Does belief matter in climate change action? Public Underst. Sci. 2011, 21, 1-14.

58. Tobler, C.; Visschers, V.H.; Siegrist, M. Addressing climate change: Determinants of consumers' willingness to act and to support policy measures. J. Environ. Psychol. 2012, 32, 197-207.

59. Akter, S.; Bennett, J. Household perceptions of climate change and preferences for mitigation action: The case of the Carbon Pollution Reduction Scheme in Australia. Clim. Change 2011, 109, 417-436.

60. Schuitema, G.; Steg, L.; Rothengatter, J.A. The acceptability, personal outcome expectations, and expected effects of transport pricing policies. J. Environ. Psychol. 2010, 30, 587-593.

61. Moser, S.C.; Dilling, L. Communicating Climate Change: Closing the Science-Action Gap. In The Oxford Handbook of Climate Change and Society; Oxford University Press: Oxford, UK, $2011 ;$ p. 161.

62. Nisbet, M.C.; Scheufele, D.A. What's next for science communication? Promising directions and lingering distractions. Am. J. Bot. 2009, 96, 1767-1778.

63. Kahan, D. Fixing the communications failure. Nature 2010, 463, 296-297.

64. Hoffman, A.J. Sociology: The growing climate divide. Nat. Clim. Change 2011, 1, 195-196.

65. McCright, A.M.; Dunlap, R.E. The politicization of climate change and polarization in the American public's views of global warming, 2001-2010. Sociol. Q. 2011, 52, 155-194.

66. Cooper, C.B. Media literacy as a key strategy toward improving public acceptance of climate change science. BioScience 2011, 61, 231-237. 
67. Pidgeon, N.; Fischhoff, B. The role of social and decision sciences in communicating uncertain climate risks. Nat. Clim. Change 2011, 1, 35-41.

68. Berinsky, A. Silent Voices: Public Opinion and Political Participation in America; Princeton University Press: Princeton, NJ, USA, 2004.

69. Verba, S.; Schlozman, K.; Brady, H. Voice and Equality: Civic Voluntarism in American Politics; Harvard University Press: Cambridge, MA, USA, 1995.

(C) 2013 by the authors; licensee MDPI, Basel, Switzerland. This article is an open access article distributed under the terms and conditions of the Creative Commons Attribution license (http://creativecommons.org/licenses/by/3.0/). 